\title{
A micro-bead device to explore Plasmodium falciparum-infected, spherocytic or aged red blood cells prone to mechanical retention by spleen endothelial slits
}

Guillaume Deplaine ${ }^{1,2,3 \dagger}$, Innocent Safeukui ${ }^{1,2^{*} \dagger}$, Fakhri Jeddi ${ }^{3}$, François Lacoste ${ }^{4}$, Valentine Brousse ${ }^{5}$, Sylvie Perrot ${ }^{1,2}$, Sylvestre Biligui ${ }^{3,6}$, Micheline Guillotte ${ }^{1,2}$, Corinne Guitton7, Safi Dokmak', Béatrice Aussilhou ${ }^{8}$, Alain Sauvanet ${ }^{8}$, Anne Couvelard ${ }^{9}$, François Paye ${ }^{10}$, Marc Thellier ${ }^{3,6}$, Dominique Mazier ${ }^{3,6}$, Geneviève Milon ${ }^{11}$, Narla Mohandas ${ }^{12}$, Odile Mercereau Puijalon ${ }^{1,2}$, Peter H David ${ }^{1,2}$, Pierre A Buffet ${ }^{3,6}$

From Parasite to Prevention: Advances in the understanding of malaria Edinburgh, UK. 20-22 October 2010

Experimental tools to identify human red blood cells (RBC) prone to mechanical retention upstream from the spleen venous sinus inter-endothelial slits are currently suboptimal. We designed a micro-bead device mimicking the geometry of the human narrow and short inter-endothelial slits. Upon filtration through a mixture of 5-25 $\mu \mathrm{m}$ diameter micro-beads, Plasmodium falciparum-hosting RBC (Pf-RBC) were retained in a parasite developmental stage-dependent way, the retention rates of a subset of ring-RBC being similar in micro-beads and in isolated-perfused human spleens. We found that this retention might be linked principally to the reduced surface-area-to-volume ratio of $P f-R B C$. Interestingly, other rigid $\mathrm{RBC}$, such as heat-treated $\mathrm{RBC}$, and $R B C$ from hereditary spherocytosis patients were also retained in micro-beads without any hemolysis. Micro-beads allow (i) depletion of heterogeneous RBC population from its rigid-RBC subpopulation ii) characteriziation of distinct molecular signatures of rigid versus deformable RBC subpopulations. This simple method portends wide medical applications, such as improving the quality of stored $\mathrm{RBC}$ concentrates prior to transfusion.

\section{Author details}

'Institut Pasteur, Unité d'Immunologie Moléculaire des Parasites, Département de Parasitologie Mycologie, F- 75015 Paris, France. ${ }^{2}$ CNRS, URA2581, Paris, France. ${ }^{3}$ INSERM - UPMC (Paris 6 University) UMRs945, F-75013 Paris, France. ${ }^{4}$ Fond Ackermann, Fondation de France. ${ }^{5}$ Department of Pediatrics, Necker Hospital, AP-HP, F-75015 Paris, France. ${ }^{6}$ Department of Parasitology, Pitié Salpétrière Hospital, AP-HP, F-75013 Paris, France. ${ }^{7}$ Department of Haematology, Kremlin-Bicêtre Hospital, AP-HP, F-94270 Le Kremlin-Bicêtre, France.

${ }^{8}$ Department of Surgery, Beaujon Hospital, AP-HP, F-92110 Clichy, France. ${ }^{9}$ Department of Pathology, Beaujon Hospital, AP-HP, F-92110 Clichy, France. ${ }^{10}$ Department of Surgery, Saint-Antoine Hospital, AP-HP, F-75018 Paris, France. ${ }^{11}$ Institut Pasteur, mmunophysiologie et Parasitisme Intracellulaire, Département de Parasitologie Mycologie, F-75015 Paris, France. ${ }^{12}$ New York Blood Centre, New York, NY 10065, USA.

Published: 20 October 2010

\section{doi:10.1186/1475-2875-9-S2-010}

Cite this article as: Deplaine et al:: A micro-bead device to explore Plasmodium falciparum-infected, spherocytic or aged red blood cells prone to mechanical retention by spleen endothelial slits. Malaria Journal 2010 9(Suppl 2):010.

\footnotetext{
† Contributed equally

'Institut Pasteur, Unité d'Immunologie Moléculaire des Parasites, Département de Parasitologie Mycologie, F- 75015 Paris, France

Full list of author information is available at the end of the article
}

(c) 2010 Safeukui et al; licensee BioMed Central Ltd. This is an open access article distributed under the terms of the Creative Commons 